Eugenio Coseriu

\title{
Diez tesis a propósito de la esencia del lenguaje y del significado ${ }^{1}$
}

\author{
Traducción de Mónica Castillo Lluch y Johannes Kabatek
}

\section{Prioridad absoluta del lenguaje}

El error fundamental de la mayoría de las teorías (o "filosofías") del lenguaje consiste en querer reducir el lenguaje a alguna de las otras facultades (o actividades libres) del hombre: al entendimiento (el pensamiento racional), al espíritu práctico o al arte, cuando lo cierto es que el lenguaje no se deja reducir a "otra cosa". El lenguaje - y Hegel fue quien se dio cuenta de ello - es una de las dos dimensiones esenciales del ser del hombre, siendo la otra el trabajo. El hombre es el único ser que, en el sentido propio de estos términos, trabaja y habla. Mediante el trabajo, el hombre se construye sin cesar un mundo apropiado a su ser físico, mientras que mediante el lenguaje se construye un mundo apropiado a su ser espiritual: un mundo pensable (el mundo de la experiencia sensible, aunque es representable, no es pensable). De ahí que el lenguaje sea "el acceso" a todas las posibilidades culturales del hombre (incluidos el pensamiento discursivo, la ciencia, la filosofía, la poesía). En este sentido, Hegel constataba que el lenguaje era "voreilig" ya que contiene de antemano todas las formas del desarrollo del espíritu. Todos los demás rasgos característicos del lenguaje derivan de este hecho fundamental. $^{2}$

1 Este texto es una traducción del manuscrito que lleva el número A 350 en la clasificación del Archivo Coseriu (que forma parte de los manuscritos que se añadieron posteriormente a la clasificación hecha en los años noventa y consultable bajo www.coseriu.de/klassif.htm ). El título de la versión original francesa es Quelques thèses à propos de l'essence du langage et du signifié. El texto fue originalmente enviado, en una versión previa, a los participantes de un seminario celebrado en Estrasburgo, del 7 al 10 de octubre de 1999, en el marco del coloquio Perception du monde et perception du langage. La versión enviada por Coseriu el 14 de octubre, así como los apuntes previos a esta versión se pueden consultar aquí Más tarde, el texto fue publicado dos veces, por un lado, en versión en línea, en la revista electrónica Texto (véase http://www.revue-texto.net/Inedits/Coseriu_Theses.html ), y, por otro lado, en versión impresa, en Keller, D. / Durafour, J. P. / Bonnot, J. F. P. / Sock, R. (éds.): Percevoir: monde et langage. Invariance et variabilité du sens vécu, Sprimont: Mardaga 2001, p. 79-92. Una primera traducción al español, de Federico Pastene Labrín, fue publicada en la revista Literatura y Lingüística 17 (2006),327-331. Aun así, nos pareció oportuno traducir el texto de nuevo, intentando reproducir el texto original de la manera más fiel posible y teniendo en consideración tanto el manuscrito original como las correcciones del autor. Existen otros textos afines, como las tesis publicadas en español en la revista Lexis en 1998 ("Tesis acerca del "significado", Lexis, XXII, 1 (1998), Lima, 83-86), así como fichas en el Archivo Coseriu con apuntes de temática semejante, que hemos tenido en cuenta a la hora de preparar la traducción.

Se trata de uno de los últimos textos de Coseriu, uno de los más densos resúmenes de su concepción del lenguaje, esbozo fundamental del pensamiento coseriano, muestra de la unidad de un edificio de pensamiento configurado ya en los años 50 y reafirmación de su validez también frente a los desarrollos de la neurobiología y las ciencias de la cognición, debatidos durante aquel coloquio. Una discusión de las ideas aquí presentadas se encuentra en J. Kabatek, "Eugenio Coseriu, las tesis de Estrasburgo y el postulado de una lingüística lingüística", en prensa.

2 Esta idea y la referencia a Hegel es fundamental para la concepción del lenguaje de Coseriu y se encuentra repetidas veces a lo largo de su obra, cf. también el siguiente pasaje: "Es ist etwas anderes, wenn man sich fragt, was eine Interpretation der Sprache zur Interpretation des Menschen beitragen könnte. Da bin ich schon überzeugt, daß die Sprache gerade das Definitorische des Menschen ist und daß deshalb auch Hegel die Sprache nicht als eine Form des Geistes oder der Kultur ansieht, sondern als eine Dimension der Menschlichkeit, noch vor der Differenzierung des Geistes, und zwar neben der Arbeit. Die Sprache ist in der 


\section{Lenguaje y cultura}

El lenguaje es actividad creadora y, como tal, es actividad "cultural" infinita; pero al mismo tiempo es una forma de la cultura y la base de la cultura, en particular, en cuanto tradición cultural.

\section{Los universales del lenguaje}

El lenguaje se caracteriza por cinco universales - tres universales primarios: creatividad, semanticidad, alteridad, y dos universales secundarios o derivados: historicidad y

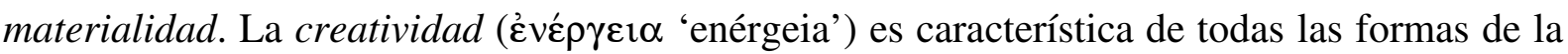
cultura. Entre estas, el lenguaje es la actividad que crea significados, signos con significaciones, y de ahí su semanticidad. Sin embargo, estos signos son siempre creados "para el otro", o, mejor dicho, como si fueran ya de antemano del otro, y de ahí su alteridad. En este sentido, el lenguaje es la manifestación primaria de la alteridad: de ese "ser con el otro" característico del hombre. La historicidad resulta de la creatividad y de la alteridad, y significa que la técnica de la actividad lingüística se presenta siempre bajo la forma de sistemas tradicionales propios de comunidades históricas, sistemas que se llaman lenguas. Incluso lo que se crea en el lenguaje se crea siempre en una lengua. La materialidad, por su parte, resulta de la semanticidad y la alteridad: la semanticidad es un hecho de la mente y no sale de ella; para que pueda ser "para otro", tiene que estar representada en el mundo sensible por significantes materiales. Sin duda, sucede otro tanto con las demás actividades culturales, cuyos contenidos, como es sabido, se constituyen únicamente en la mente y deben todos estar "representados" en el mundo sensible. Aun así, la materialidad del lenguaje es diferente de la de las otras actividades culturales, ya que es siempre materialidad específica de una lengua. Así ocurre también con la historicidad de las otras actividades culturales, y de este modo, los "estilos" del arte no son análogos a las lenguas.

Obsérvese además que el lenguaje es la única actividad cultural definida por dos universales (semanticidad y alteridad), y no por uno solo, y que en él la alteridad se halla triplemente presente, ya que condiciona también la historicidad y la materialidad.

\section{Comunicación y comunidad}

El lenguaje (en cuanto decir), desde luego, es “comunicación”. Pero hay que distinguir entre la comunicación de algo - hecho práctico y que puede también no darse sin que por ello el lenguaje deje de ser tal - de la comunicación con el otro, sin la cual el lenguaje ya no es

ewigen Idealgeschichte der Entwicklung des Menschen "voreilig", weil sie alles Geistige schon im voraus enthält, wenn auch als noch nicht differenziert. Sie ist - wie ich es einmal formuliert habe - das "InErscheinung-Treten des Menschlichen" und die "Eröffnung aller (geistigen) Möglichkeiten des Menschen". Deshalb nehme ich mit Hegel und mit Hegelscher Begründung eben die Arbeit und die Sprache als Grunddimensionen des Wesens des Menschen an. Die Arbeit für den Menschen als biologisches Wesen, die Sprache für den Menschen als denkendes Wesen. Beide Dimensionen können ihrerseits auf die ursprüngliche Negativität des Menschen zurückgeführt werden - auf den "luziferischen Charakter des Menschen" als eines Wesens, das die Welt nicht so annimmt, wie sie ihm gegeben ist, sondern die Welt ändert oder sich eine eigene Welt konstruiert, die für seine sich immer weiter entwickelnden Bedürfnisse geeignet ist, so daß die Welt des Menschen in beiderlei Hinsicht unendlich ist. Unendlich in biologischer Hinsicht, weil immer wieder neue Bedürfnisse geschaffen werden und neue Modifizierungen der naturgegebenen Welt stattfinden; unendlich im geistigen Bereich, weil das Denken und die Kreativität nie zu einem Ende kommen.” (E. Coseriu en: Kabatek, J. / Murguía, A. (1997): „Die Sachen sagen, wie sie sind... “. Eugenio Coseriu im Gespräch, Tübingen: Narr 1997. 
lenguaje y que se da sin falta (está presente ya en la creación de los significados), pues corresponde a la alteridad fundamental del lenguaje. En lo que concierne a la comunidad, el lenguaje no es simplemente un "hecho social", un "producto" de la sociedad comparable a las "instituciones" sociales; es, bien al contrario (Aristóteles bien lo vio en su Politeia), debido a la alteridad, el fundamento de toda asociación humana.

\section{Nombrar y decir}

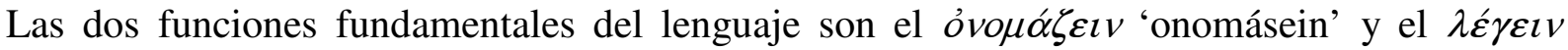
'légein' (Platón): nombrar y decir (lo que más o menos corresponde a la distinción entre léxico y gramática). Pero mientras que en el "nombrar" (primario) todo es lenguaje (ya que se trata de la organización del mundo en categorías y especies), en el "decir" (donde se trata de establecer relaciones en este mundo y con este mundo), es solo la "forma" genérica - la modalidad semántica - de estas relaciones la que es propiamente "lenguaje" puesto que, en cuanto a su sustancia, el decir es también ciencia, actividad práctica, sentimiento, arte (poesía), etc.

\section{Contenido del "decir"}

En el contenido "expresado" y "comunicado" por el "decir", hay que distinguir entre designación, significado y sentido. La designación es la referencia a las "cosas" ("estados de cosas", "acontecimientos", "procesos") extralingüísticas (o, mejor, exteriores a los signos). El significado es la posibilidad objetiva de designación dada en los signos de una lengua. Por último, el sentido es la finalidad de cada "decir", el contenido propio de un discurso como tal (o de un fragmento de un discurso). Así, la constatación, la réplica, la respuesta, la pregunta,

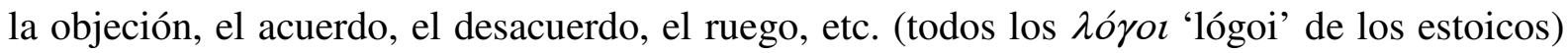
son unidades de sentido (y no de "significación"). Desde el punto de vista lingüístico, el sentido es la finalidad del discurso en cuanto que viene dado (expresado) por el significado (léxico, categorial, gramatical, "óntico") y la designación; pero a la constitución del sentido contribuyen también el conocimiento de las "cosas" y los "entornos". El contenido propiamente y exclusivamente linguiístico es, por consiguiente, el significado.

\section{Lenguaje y poesía}

Como identificación de una modalidad del ser, el significado es un acto de conocimiento, y, al igual que la poesía (y el arte en general), de conocimiento intuitivo concretamente. Esto ha conducido a ciertos filósofos a identificar lenguaje y poesía, por lo menos en cuanto a los actos primarios de creación. Aun así, el significado (y, por consiguiente, el lenguaje) no es idéntico a la poesía. Por un lado, el significado siempre es obra de un sujeto dotado de alteridad, mientras que la poesía (y el arte en general) es obra de un sujeto absoluto (que se presenta como absoluto). Por otro lado, el lenguaje como tal no es más que significado (léxico, categorial, gramatical, "óntico"), mientras que la poesía es un "decir" con su propia sustancia. Los filósofos que identifican lenguaje y poesía solo consideran el lenguaje como "decir" (y como "decir" de un sujeto absoluto). Nosotros postulamos, en cambio, la prioridad del lenguaje también frente a la poesía. Y esto no quita que el lenguaje poético sea el lenguaje en su plenitud funcional. 


\section{Significado y ser}

El significado de un nombre (o, mejor dicho, el significado en cuanto nombre) es

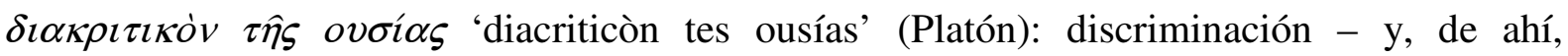
constitución - de una modalidad (siempre virtual) del ser. En sí, el significado de un nombre siempre es universal ya que no nombra "entes" reconocidos como tales sino una posibilidad infinita del ser. No se halla al final, sino al principio de la constitución de una "clase" (la cual, con respecto al mundo "real", también puede ser una clase de un solo miembro conocido, por ejemplo sol, luna - o incluso una clase vacía). Por lo tanto, la designación no es lo primero y principal del lenguaje, sino un hecho secundario: es el hecho de asociar una "cosa" reconocida a un significado ya dado. El nombre propio es, en el lenguaje, un hecho secundario: es un nombre de identificación histórica de un ente dentro de una clase ya reconocida como tal.

\section{Significado, verdad y existencia}

El significado (y, de ahí, el lenguaje como tal) no es ni verdadero ni falso: es anterior a la distinción misma entre verdadero y falso. Además, como no representa más que una modalidad virtual (una posibilidad) del ser, el significado es anterior a la distinción entre existencia y no-existencia (Aristóteles). Solo puede ser verdadero o falso el "decir" en cuanto proposición ( $\lambda o ́ \gamma o \varsigma \alpha ̉ \pi o \varphi \alpha v \tau \imath \kappa o ́ \varsigma$ 'lógos apofánticos'). Del mismo modo, solo conociendo un significado se puede reconocer la existencia de entes designables que le corresponden. Esto es lo que llamo el "carácter deíctico" del lenguaje; un nombre "muestra" una modalidad del ser (o, mejor dicho, la constituye y la representa), pero no dice nada acerca de ella (los nombres derivados y los nombres compuestos, en cambio, contienen ya un "decir" o, desde el punto de vista lingüístico, cierta "gramaticalización”).

\section{Lenguaje y “cosas"}

El lenguaje es lo que confiere el ser a las "cosas" y no una nomenclatura para clases de "cosas" ya reconocidas de antemano como tales. Obviamente, el lenguaje no crea los "entes", sino su "ser": los hace ser esto o aquello. Así, el lenguaje no crea los árboles, sino su "ser árboles" (y no, por ejemplo, ser plantas en general u otra especie cualquiera). De este modo, el lenguaje nos conduce hacia un mundo ordenado de "cosas". Delimitando las modalidades del ser, permite constatar o reconocer en el "mundo" entes correspondientes a esas modalidades y ofrece así la posibilidad de la búsqueda de las "cosas" mismas, y, por consiguiente, la posibilidad de nuevas delimitaciones, ahora sí "objetivas": reconocidas en el mundo mismo de las "cosas" y nombrables mediante nombres creados (o "términos"). Toda ciencia comienza necesariamente por las clasificaciones dadas en el lenguaje, pero no se detiene en estas clasificaciones. Es así como surge el "lenguaje técnico" (o "terminología"). Toda terminología (incluida la terminología de la "ciencia popular") es, en este sentido, lo contrario del lenguaje originario (no terminológico): va de la designación a la significación y nombra efectivamente clases reconocidas de antemano como tales. Con todo, el lenguaje técnico solo se puede constituir de manera secundaria, partiendo de las delimitaciones ya realizadas en y por el lenguaje no técnico. 